\title{
Contribuciones para analizar las identificaciones sociales desde la teoría de la hegemonía
}

\author{
Contributions to analyze social identifications \\ from the theory of hegemony
}

\author{
Hernán Fair (D) http://orcid.org/0000-0002-2082-8257 \\ Universidad Nacional de Quilmes,Argentina, hernanfair@conicet.gov.ar
}

Recepción: 22/09/2021

Aprobación: 22/11/2021

Publicación: 25/01/2022

\begin{abstract}
This article analyses the topic of identifications in Ernesto Laclau's theory of hegemony, focusing on the crosses between the leader and the function of Lacan's object a. Based on a reading of On populist reason, the paper proposes an innovative typology with three modes of social identification for discourse analysis: direct identification with the political leader; indirect identification around the leader mediated through a partial object that becomes an empty signifier and function by a nodal point; and the identification with certain values, principles, demands or shared ideals by the group or organization that function as objects cause of desire. In the second part, it deploys some useful theoretical-methodological tools to deepen and strengthen the social investigation of contemporary sociopolitical identities and processes from the political theory of discourse.
\end{abstract}

Key words: identifications, political leader, object a, demand, theory of populism.

Resumen: Este artículo analiza la cuestión de las identificaciones en la teoría de la hegemonía de Ernesto Laclau, centrándose en los cruces entre el líder y la función del objeto a de Lacan. A partir de una lectura de La razón populista, el trabajo propone una tipología innovadora basada en tres modos de identificación social para el análisis del discurso: la identificación directa con la figura del líder político; la identificación indirecta en torno al líder mediada a través de un objeto parcial que se convierte en significante vacío y ocupa el rol de punto nodal; y la identificación con ciertos valores, principios, demandas o ideales compartidos por el grupo u organización que funcionan como objetos a causa de deseo. En la segunda parte, se despliegan algunas herramientas teórico-metodológicas útiles para profundizar y fortalecer la investigación social de identidades y procesos sociopolíticos contemporáneos desde la teoría política del discurso.

Palabras clave: identificaciones sociales, líder político, punto nodal, demanda, teoría del populismo. 


\section{Introducción $^{1}$}

El presente trabajo se propone analizar la cuestión de las identificaciones sociales en la teoría discursiva de la hegemonía de Laclau. Específicamente, se centra en el análisis de los cruces entre el líder y la función del objeto a de Lacan en la teoría del populismo. De este modo, se espera contribuir a complejizar y fortalecer el análisis discursivo de identidades y procesos políticos y sociales contemporáneos, desde la perspectiva laclauiana. ¿Cómo aborda Laclau la temática de las identificaciones en La razón populista? ¿Qué papel adquiere el líder populista y cómo se entrecruza con el concepto de objeto a en la ligazón afectiva? ¿Qué aportes contiene La razón populista para fortalecer el estudio de las identificaciones sociales en la dinámica de la operación hegemónica?

Para responder a estas interrogantes, el texto se estructura en dos partes. En la primera parte, se analiza la cuestión de las identificaciones en la teoría del discurso de Laclau, con énfasis en las especificaciones sobre el rol del líder, el papel de las demandas y la función del objeto a en La razón populista. En la segunda parte, se propone una tipología con tres modos de identificación para el análisis sociopolítico. Se ilustra con algunos ejemplos históricos para mostrar el funcionamiento del artefacto teórico en la dinámica política y se despliegan algunas herramientas analíticas útiles para la investigación social.

\section{La cuestión de las identificaciones en la teoría de la hegemonía de Laclau}

Laclau menciona el concepto de identificación por primera vez en Nuevas reflexiones sobre la revolución de nuestro tiempo. En esta etapa, influido por Lacan y por Derrida, el teórico político argentino relaciona al sujeto con un "acto de identificación" que tiene lugar en el terreno de una "falla estructural" (Laclau, 1993: 60, 76 y ss.). En Minding the gap (escrito en coautoría con Lilian Zac), Laclau define al sujeto como "sujeto de la falta" y afirma que es capaz de realizar "actos de identificación” (Laclau y Zac, 2002: 12 y ss.). Por su parte, en "Deconstrucción, pragmatismo, hegemonía, Laclau caracteriza

1 Este artículo es patrocinado por el Consejo Nacional de Investigaciones Científicas y Técnicas (CONICET) y se inscribe, a su vez, en el marco del Proyecto de Investigación Científica y Tecnológica (PICT) "Análisis Político del Discurso e identidades políticas: estrategias teórico-metodológicas para investigar la construcción de hegemonía y el impacto hegemónico en la Argentina reciente", financiado por la Agencia Nacional de Promoción de la Investigación, el Desarrollo Tecnológico y la Innovación (AGENCIA I+D), Ministerio de Ciencia, Tecnología e Innovación, República Argentina. 
al sujeto como un "agente de decisión" y capaz de "generar identificaciones" en el terreno de una "identidad estructural fallida" (Laclau, 1998: 114 y ss.). En ese marco, sostuvo que "no tenemos simplemente identidades, sino, más bien, identificación” (Laclau, 2003: 63).

Sin embargo, es recién en su última etapa -que se inicia con la publicación de La razón populista (de ahora en adelante: LRP) - cuando Laclau profundizó en los cruces con el psicoanálisis y en el abordaje específico de las identificaciones sociales, desde una perspectiva posfundacional (Merlin, 2015; Ipar, 2020). En este texto, Laclau (2005) abordó la relación entre hegemonía, identificaciones y el rol del líder, lo cual le generó diferentes críticas por sus simplificaciones, imprecisiones, ambigüedades e inconsistencias en relación con los conceptos de objeto a, pueblo, demandas y heterogeneidad, su relegamiento de los aspectos institucionales y su tendencia a reducir el carácter plural de la operación hegemónica a la figura del líder populista (Aboy Carlés, 2005; Barros, 2009 y 2018; Retamozo, 2009, 2017 y 2021; Arditi, 2010; Gutiérrez Vera, 2011; Sosa, 2011; Fair, 2019a y 2019b; De Cleen y Glynos, 2021).

En el marco de estas críticas, Emilio De Ípola (2009), uno de sus principales lectores, le objetó a Laclau el olvido de los aportes de Freud de otros textos sociales que permiten complejizar los vínculos entre el líder y la "horda primitiva". Laclau no respondió a estas críticas. Sin embargo, hallamos algunos fragmentos en LRP en los que Laclau efectúa una relectura crítica de los textos sociales de Freud y realiza disquisiciones que contribuyen a complejizar los aportes realizados por De Ipola, en clave lacaniana. Estas contribuciones remiten, por un lado, a la función central del objeto a y de las demandas en la identificación social. Por el otro, a la distinción de diferentes modos de identificación, que se expresan a través de un continuum de gradientes en la dinámica política.

\section{La razón populista y la distinción entre dos modelos de identifi- cación política}

En La razón populista, Laclau (2005) realizó algunos aportes teóricos relevantes para el estudio de las identificaciones en la operación hegemónica. En el capítulo 1, luego de efectuar un recorrido por el concepto de identificación en las obras pioneras de Le Bon, Taine, Tarde y McDougall, Laclau incluye un apartado intitulado "El avance freudiano" (Laclau, 2005: 75). Centrándose en Psicología de las masas y análisis del yo, Laclau afirma que Freud (1973) analiza los "lazos emocionales" a partir del modelo de las 
"identificaciones" y sostiene que la identificación es "la exteriorización más temprana de un lazo afectivo con otra persona" (Laclau, 2005: 77). De acuerdo con Laclau, el "clímax" de la interpretación freudiana es la "caracterización de la formación del grupo en términos de su amor común hacia un líder” que ocupa el lugar de "yo ideal" (Laclau, 2005: 80). La conclusión de este argumento es que "la sociedad sería concebida como una masa homogénea, cuya coherencia estaría asegurada exclusivamente por la presencia del líder" (Laclau, 2005: 80). Sin embargo, Laclau señala que esta interpretación es "exagerada", ya que "el énfasis unilateral en la relación con el líder simplemente ignora todos los pasajes en el texto de Freud donde se sugieren diferentes alternativas sociales como posibilidades reales" (Laclau, 2005: 81).

Según Laclau, existe en Freud una "oposición entre dos modelos de agrupamiento social alternativos”. En el primero, la unidad del grupo se produce en torno al "vínculo libidinal con el líder" (Laclau, 2005: 82). En el segundo, la unidad está "basada en la organización, mediante la cual la sociedad adquiere las características secundarias del individuo" (Laclau, 2005: 82). Luego, afirma que estos dos ejemplos "constituyen más bien lógicas sociales que, en diversos grados, influyen en la constitución de todos los grupos" (Laclau, 2005: 82).

A continuación, Laclau realiza un nuevo aporte que consideramos fundamental para la investigación social. Laclau afirma que el grupo completamente organizado y la identificación absoluta con el líder constituyen dos extremos "imposibles" y que estas dos lógicas sociales se articulan entre sí mediante un "continuum" en la dinámica política:

Desde mi punto de vista, el grupo completamente organizado y el líder puramente narcisista son nada más que la reducción al absurdo, es decir, imposible, de los extremos de un continuum en el cual las dos lógicas sociales se articulan de diversas maneras (Laclau, 2005: 82).

Luego, Laclau retoma algunos ejemplos en los cuales Freud analiza dicha “combinación” y que permiten aseverar que:

Ese algo en común que hace posible la identificación entre los miembros del grupo no puede consistir exclusivamente en el amor por el líder, sino en algún rasgo positivo compartido por el líder y los liderados (Laclau, 2005: 83).

En la parte final del capítulo 1 de LRP, Laclau afirma que a partir de este "sistema de alternativas", se puede abordar la "cuestión del populismo" (Laclau, 2005: 87), aunque ello presupone ir más allá de Freud para "apelar a una pluralidad de tradiciones intelectuales" (Laclau, 2005: 88).

En el capítulo siguiente, Laclau recupera las dos modalidades de identificación del grupo y señala que la organización que asume todas las funciones 
del individuo y elimina al líder es "imposible". Pero, del mismo modo, "su antípoda, un grupo duradero cuyo único lazo libidinal es el amor por el líder, es igualmente imposible" (Laclau, 2005: 109).

De esta manera, Laclau dejó abierta una doble posibilidad para el análisis político. Por un lado, señaló que el líder es condición de posibilidad de la unidad del grupo y, por ende, de la hegemonía. En este sentido, "la unificación del grupo en torno a una individualidad es inherente a la formación de un pueblo" (Laclau, 2005: 130). Aunque al mismo tiempo aclaró que "la forma extrema de singularidad es una individualidad” (Laclau, 2005: 130).

Sin embargo, Laclau también cuestionó a Freud por la supuesta centralidad del líder como eje de la identificación. Según Laclau, si bien el amor hacia el líder resulta un elemento central para constituir todo vínculo político:

Freud se apresura demasiado en pasar de apuntar el amor por el líder como condición central de la consolidación del vínculo social, a la afirmación de que él constituye el origen de ese vínculo (Laclau, 2005: 109; el subrayado y las negritas son míos).

Según Laclau (2005: 109), esta interpretación es “insuficiente” y debe complementarse con las referencias de Freud a la "graduación" (Laclau, 2005: 110). De este modo, Laclau abre la posibilidad de abordar una segunda alternativa, en la cual la identificación no se centra en la figura casi hipnótica del líder, sino en su función de ordenamiento social. El líder representa aquí una especie de articulador "en última instancia" del grupo, que consolida elementos dispersos de la cadena significante. De manera tal que el líder no es el origen necesario del vínculo social, pero sí funciona como su articulador final.

Estas contribuciones permiten analizar en la dinámica política diferentes formas de identificación social, a través de un continuum de gradientes relativos. Por un lado, existiría un caso extremo basado en la identificación directa con la figura del líder como significante Amo. Por el otro, habría una identificación social opuesta a la anterior, centrada en la organización (por ejemplo, un partido político), o en una idea política aglutinadora (por ejemplo, la idea de socialismo), sin un liderazgo político. Entre ambos extremos, tenemos un continuum de opciones intermedias.

\section{El ejemplo histórico extremo del último Perón en La razón populista}

En LRP, Laclau destacó algunos ejemplos históricos que tienen implicancias para el abordaje de los modos de identificación social y, en particular, para estudiar el rol de los liderazgos populistas. En el apartado "El retorno de Perón”, el historiador argentino retomó el ejemplo de Perón de 1973, cuando 
el líder populista retornó del exilio forzado en España para unificar al disgregado movimiento peronista (Laclau, 2005: 266 y ss.).

A partir de contribuciones de un clásico texto de Sigal y Verón (2003) y de un trabajo de Castagnola (2000), Laclau señalala particular conformación histórica del movimiento peronista con su líder máximo en el exilio (19551973) y, en particular, "las condiciones mismas de enunciación del discurso de Perón desde el exilio". Estas condiciones enunciativas del discurso de Perón se basaron en la difusión de discursos con una "multiplicidad de sentidos" y "deliberadamente imprecisos", dirigidos tanto hacia la izquierda como a la derecha del movimiento peronista, para asegurar su aura de "infalibilidad" (Laclau, 2005: 268-269).

Las características particulares del discurso de Perón en el exilio (en un contexto de violencia política y fuerte polarización social) le permitieron a Laclau mostrar la existencia de un significante (el propio Perón) que, coyunturalmente, se volvió "completamente vacío" (Laclau, 2005: 270). De este modo, todos los elementos particulares de la cadena de equivalencias se aglutinaron en torno a la figura del líder popular. Sin embargo, como indica Laclau, la coyuntura previa al regreso de Perón desde su exilio se trataba de una situación "extrema" en la cual el amor por el padre es el único lazo social. Ello hace que, en esas circunstancias, la unidad del pueblo sea muy frágil y endeble. Además, la ausencia de una regularidad institucional sólo puede generar identidades populares "efímeras":

De acuerdo con Freud: ésta sería la situación extrema en la cual el amor por el padre es el único lazo entre los hermanos. La consecuencia política es que la unidad de un pueblo constituido de esta manera es extremadamente frágil. Por un lado, el potencial antagonismo entre demandas contradictorias puede estallar en cualquier momento; por otro lado, un amor por el líder que no cristaliza en ninguna forma de regularidad institucional -en términos psicoanalíticos, un yo ideal que es internalizado parcialmente por los yoes corrientes- sólo puede resultar en identidades populares efímeras (Laclau, 2005: 270; el subrayado y las negritas son míos).

Estas especificaciones conceptuales de Laclau son relevantes, ya que permiten ir más allá de la identificación directa con la figura hipnótica del líder populista, para destacar la importancia de las formas de sedimentación institucional. ${ }^{2}$

2 En trabajos posteriores a LRP, además, Laclau profundizó en las combinaciones históricas entre elementos populistas e institucionalistas en los gobiernos de centro-izquierda de América Latina y mostró que no existe una disyunción óntica entre populismo e institucionalismo (Laclau, 2006a). 


\section{Las críticas de Laclau a Freud y la influencia de la teoría lacaniana}

Vimos las vicisitudes del concepto de identificación en Freud, que representaron un "avance" frente a los análisis previos de la psicología política. Sin embargo, en LRP Laclau indica que Freud asumía un abordaje principalmente genético de su objeto de estudio, que requiere reformular su teoría para que sea una herramienta útil para el análisis sociopolítico:

Freud, como resultado del marco psicoanalítico dentro del cual construye su teoría, tiene una aproximación predominantemente genética hacia su objeto de estudio. Por ello sus categorías obviamente requieren de una reformulación estructural si van a ser útiles como herramientas del análisis sociopolítico" (Laclau, 2005: 87, el subrayado y las negritas son míos).

De hecho, como señala la psicoanalista Nora Merlin (2015), la concepción freudiana de la identificación de la masa con el líder como ideal del yo de Psicología de las masas y análisis del yo no representa una modalidad discursiva del lazo social ni implica una construcción política, ya que presupone la existenciade una masa pasiva, servil, uniforme e indiferenciada, enceguecida de un modo religioso por su adoración fanática al líder:

Este fenómeno no constituye una modalidad discursiva de lazo social, sino que se puede describir como un montón de gente seriada, indiferenciada y unificada por identificación y obediencia al líder. El sujeto de la masa es pasivo, servil y sugestionado, su yo empobrecido revitaliza la vieja retórica moralizante y predestinada. Freud vio en la psicología de las masas al rebaño, la fascinación colectiva, un prolegómeno del totalitarismo. ¿Se puede pensar que ella es una construcción política? La respuesta es negativa, porque una formación sostenida exclusivamente en el amor lleva necesariamente a la religión, en la cual el líder es una imagen-ídolo que se adora. Ya demostramos que el amor siempre enceguece y tiende a pacificar las relaciones, encubriendo el conflicto o el desacuerdo. Por lo tanto, esta concepción es contraria a la política (Merlin, 2015: 45-46).

El propio Laclau sostiene que LRP no debe considerarse un "ejercicio freudiano”. En cambio, para investigar fenómenos y procesos políticos y sociales actuales se debe ir más allá de Freud, para articular diferentes tradiciones intelectuales:

Aunque tomamos a Freud como punto de partida, este libro no debería concebirse como un ejercicio freudiano. Hay muchas cuestiones que Freud no trató, y muchos caminos, bastante importantes para nuestros propósitos, que él no siguió. Por eso es que nuestra investigación debe apelar a una pluralidad de tradiciones (Laclau, 2005: 87; el subrayado es mío). 
Esta convocatoria a ir más allá de Freud y reformular estructuralmente sus aportes para el análisis sociopolítico, Laclau la realiza desde un marco lacaniano.

La Teoría Política del Discurso estuvo, desde sus inicios, fuertemente influida por las contribuciones del psicoanálisis lacaniano. Además de la concepción discursivista de lo social, encontramos convergencias casi calcadas en el análisis de las cadenas equivalenciales ("cadenas significantes"), que se unifican en torno a un significante central ("Amo") que actúa como punto nodal (point of capiton). Todos estos conceptos remiten a elementos destacados por Lacan (2006) en su Seminario 17. Laclau también menciona otros conceptos lacanianos en el transcurso de su obra, como la primacía del significante sobre el significado $(\mathrm{S} / \mathrm{s})$, la sutura, la imposibilidad de la sociedad (análogo a "No hay relación sexual”), el goce, lo imaginario y la dislocación (análogo al concepto de lo Real lacaniano), y también comparte con Lacan la concepción del sujeto como falta (lack). No obstante, mientras que Lacan enfatizó en el aspecto imaginario del vínculo social, Laclau se centró en su aspecto simbólico y dejó a un lado otros conceptos clave de la teoría lacaniana, como las fantasías, el síntoma, la teoría de los cuatro discursos y el nudo borromeo y subdesarrolló otras, como el goce y la dimensión afectiva (Stavrakakis, 2010; Gutiérrez Vera, 2011; Sosa, 2011; Fair, 2019c).

\section{La función ontológica del objeto a y su homología con la relación hegemónica}

En su última etapa, que comienza con LRP, Laclau profundizó los cruces con conceptos de la teoría lacaniana. Luego de destacar los aportes de Lacan en torno a la "emancipación del orden del significante" frente al significado, en este texto Laclau (2005: 135) señala que "es sólo a partir del enfoque lacaniano que nos enfrentamos a una verdadera innovación: la identidad y unidad del objeto son resultado de la propia operación de nominación" (el subrayado es mío).

En el marco de la primacía del orden significante en la construcción discursiva del lazo social, Laclau destacó el rol central del punto nodal (point de capiton en Lacan) en la unificación social. Según el teórico político argentino: "Está claro que sin puntos nodales, no existiría configuración alguna" 3 (Laclau, 2005: 136). Del mismo modo, en el caso de las "identidades populares", se requiere de los puntos nodales para generar una "identificación equivalencial": "Esto es exactamente lo que hemos visto en el caso de

3 El subrayado es mío. 
las identidades populares: sin el punto nodal de una identificación equivalencial, las equivalencias democráticas quedarían en lo meramente virtual" (Laclau, 2005: 136).

En este punto, a partir de contribuciones de Žižek (1992), en LRP Laclau (2005: 133) enfatizó en el rol de la "nominación", es decir, la evocación discursiva que crea retroactivamente la realidad social. En clave lacaniana, sostuvo que "el hecho de nombrar, la nominación, puede tener el efecto retroactivo que hemos descripto". Laclau (2005: 142) definió como "investidura radical" a este momento de nominación. Ello lo condujo a destacar la centralidad de la "dimensión afectiva" (Laclau, 2005: 142) y, en particular, los "aspectos emocionales del populismo" (Laclau, 2005: 143).

A continuación, Laclau retomó aportes de Copjec (1995 y 2003) desde el campo psicoanalítico y los tradujo al análisis político para subrayar su principal "descubrimiento": el papel central del concepto de objeto a de Lacan en la operación hegemónica (Laclau, 2005: 144 y ss.).

Sintéticamente, el concepto de objeto a u objeto petit a (pequeño a) constituye uno de los principales aportes originales de la teoría lacaniana (Rabinovich, 2003: 18). Recordemos que para Lacan todo sujeto representa un sujeto "dividido" o "tachado" (\$) por efecto del lenguaje (Lacan, 1987: 207). La función de estos objetos metonímicos consiste en "tapar la hiancia que constituye la división inaugural del sujeto" (Lacan, 1987: 278). El objeto a, siempre con cierta pérdida inevitable como producto de la castración simbólica y la pérdida del objeto primordial (la Madre), se constituye como causa de deseo para el sujeto. Ello se debe a que logra suplir, imaginariamente, al "objeto de la falta", que en un inicio es la figura de la madre y, más específicamente, el pecho, indistinto de la propia imagen de la madre (Lacan, 1987: 205-206, 264-266; 2006: 13; 2008). En otras palabras, los objetos petit a representan objetos parciales que se invisten como objetos causa de deseo, en tanto permiten acceder a la imposible "relación sexual" y llenar, de un modo fantasmático, la falta estructural. Al funcionar como tapones de una ausencia, en el Seminario 7, Lacan (1990: 123) señala que en los mecanismos de sublimación, los objetos a minúscula son elevados a la “dignidad de la Cosa”.

Como indica Gutiérrez Vera (2011), los objetos petit a son relevantes para el análisis sociopolítico, ya que en torno a este significante Amo se cristalizan las identificaciones:

Para Lacan, tal es la función ortopédica que cumple el objeto petit a -a la vez objeto causa del deseo y objeto del deseo-, que viene a obturar la falta, la insoportable condición incompleta (no-toda) del "sistema" político y de la sociedad, elevando a la 
categoría de elemento unificador del mismo a una particularidad in-esencial. En torno a este "significante amo", "significante hegemónico", o "punto nodal", se cristalizan las identificaciones que hacen efectiva la interpelación política (Gutiérrez Vera, 2011: 160).

La noción lacaniana de objeto a, además, resulta fundamental para descentrar al papel del líder de la horda primitiva de la teoría freudiana y valorizar a la función materna. En contraste con la concepción freudiana, donde la identificación de la masa se centra en la figura casi hipnótica del líder (sea religioso, político o militar), Lacan se enfoca en una segunda posibilidad, que relaciona la identificación con un rasgo particular del objeto.

Como ya lo indicara en el Seminario 9: La identificación (Lacan, 19611962), en el Seminario 11, Lacan sostiene que la identificación del sujeto puede ser instaurada tanto en la función del líder como ideal del yo (I), como en un objeto privilegiado al que "la pulsión le da la vuelta". Este objeto privilegiado que sirve de soporte es el objeto a minúscula (Lacan, 1987: 264-266). En este caso, la identificación no se establece con el líder como un "ideal del yo" compartido por las masas y que provee seguridad y reprime los instintos. En cambio, atraviesa el plano de la "identificación primaria narcisista" para generar una identificación con un "objeto privilegiado", que Lacan define como "objeto a" (Lacan, 1987: 265).

En el Seminario 17, El reverso del psicoanálisis, Lacan (2006) cuestionó la construcción "mítica" del "Complejo de Edipo" y la teoría del "Padre de la horda primitiva" de Freud, a partir de una relectura de Psicologia de las masas. En este texto, Lacan "se refiere a Edipo y Moisés y demuestra la inconsistencia de esas dos figuras juntas" (Laurent, 1992: 13). Lacan sostiene que el padre está "castrado" por el orden significante y reafirma que el líder no necesariamente representa al significante Amo (S1) que funciona como punto de capiton, el cual acolchona la cadena significante (S2). Según afirma, "el lugar del agente, sea el que sea, no es siempre el del significante amo” (Lacan, 2006: 185). En otras palabras, el significante Amo no siempre corresponde a la figura del líder.

Lacan advierte sobre la posibilidad de una identificación mediada por algún rasgo del objeto, ya sea un rasgo de la figura del líder (Lacan llega a referirse al ejemplo del bigote de Hitler para explicar la identificación con su figura durante el nazismo), o algún aspecto particular que genera ligazones afectivas (como la transferencia catexial a través del "supuesto saber", que resulta clave para explicar la eficacia simbólica del analista ${ }^{4}$ ). También se

4 Refiriéndose a la función del analista como Sujeto supuesto Saber, en el Seminario 11, Lacan (1987: 276) ejemplifica con la siguiente frase: "Amo en ti algo más que tú, el objeto a minúscula”. 
refiere al goce vinculado al consumo de gadgets o letosas, en el sentido de las mercancías que ofrece el Discurso Capitalista como deseantes y convertidos en objetos causa de deseo, en una lógica de pulsión circular que atrapa a los sujetos (Lacan, 2006).

Como lo han destacado diversos autores, la interpretación lacaniana del objeto pequeño a (petit a) como una construcción del orden significante que suple metonímicamente al objeto primordial del deseo (la Cosa, en tanto perdida) y llena imaginariamente la división constitutiva del sujeto, cuestiona la centralidad del líder de la horda de Freud y permite analizar diferentes modos de identificación social que van más allá de la identificación hipnótica de las masas con la figura del Padre-Líder (Laurent, 1992: 37-38; Rabinovich, 2003; Stavrakakis, 2007 y 2010).

En una lógica similar, en LRP Laclau (2005) afirma que "Lacan radicaliza el pensamiento de Freud", ya que, para él, "la Cosa perdida no es una imposibilidad del pensamiento, sino un vacío del Ser". De este modo, la Cosa deja de ser "inaccesible". A diferencia de Freud, para Lacan existe la posibilidad de una recuperación parcial del "goce" de la Cosa (la Madre), que "no se pierde", pues "quedan rastros de él en los objetos parciales" (Laclau, 2005: 145). Así, se puede acceder parcialmente al goce mítico de la Cosa a través de los objetos a (como objetos parciales). En palabras de Laclau:

Si este goce no se pierde es porque quedan rastros de él en los objetos parciales. La naturaleza de estos rastros debe ser explorada cuidadosamente, porque ya no siguen el esquema de representación noúmeno/fenoménica. El objeto parcial se convierte él mismo en una totalidad, se convierte en el principio estructurante de toda la escena (Laclau, 2005: 145; el subrayado y las negritas son míos).

Laclau (2005: 146) destaca que en Lacan el objeto parcial "no es una parte de un todo, sino una parte que es el todo”. De este modo, en la pulsión es el objeto parcial (como ocurre con el pecho materno en relación con la madre) el que asume la forma de una totalidad inconmensurable:

De esta manera, el objeto parcial deja de ser una parcialidad que evoca una totalidad y $\underline{\text { se convierte }-u t i l i z a n d o ~ n u e s t r a ~ t e r m i n o l o g i ́ a ~ a n t e r i o r-~ e n ~ e l ~ n o m b r e ~ d e ~ e s a ~ t o t a l i d a d . ~}$ Lacan rompe con la noción de una díada madre/hijo, al agregar un tercer componente, separado de la madre, que es el pecho -hablando con propiedad, el objeto de la pulsión- (Laclau, 2005: 146; el subrayado es mío).

A partir de estos aportes, Laclau encuentra una homología con la teoría lacaniana para el análisis de las identidades populares:

La totalidad mítica, la díada madre/hijo, corresponde a la plenitud no alcanzada, evocada -como su opuesto- por las dislocaciones ocasionadas por las demandas insatisfechas. La aspiración a esta plenitud o totalidad, sin embargo, no desaparece 
simplemente, sino que es transferida a objetos parciales que son los objetos de las pulsiones. En términos políticos, esto es exactamente lo que hemos denominado una relación hegemónica: una cierta particularidad que asume el rol de una universalidad imposible (Laclau, 2005: 147; el subrayado y las negritas son míos).

El "descubrimiento" original que plantea Laclau (2005) en LRP afirma que, desde el campo de la teoría política, existe una relación de identidad a nivel ontológico entre la lógica de desplazamiento del objeto a (el pecho como un objeto parcial) a la Cosa (el goce mítico de la madre) de Lacan y la lógica de desplazamiento particular-universal que caracteriza a la operación hegemónica. En sus palabras:

$\underline{\text { Si la plenitud de la madre primordial es un objeto puramente mítico, no hay ningún }}$ goce alcanzable excepto a través de la investidura radical en un objeto a. Así, el objeto a se convierte en la categoría ontológica principal. Pero podemos llegar al mismo descubrimiento (no uno meramente análogo) si partimos del ángulo de la teoría política. No existe ninguna plenitud social alcanzable excepto a través de la hegemonía; y la hegemonía no es otra cosa que la investidura, en un objeto parcial, de una plenitud que siempre nos va a evadir porque es puramente mítica. La lógica del objeto a y la lógica hegemónica no sólo son similares: son simplemente idénticas (Laclau, 2005: 148-149; el subrayado y las negritas son míos).

En la lectura lacaniana de Laclau, la lógica de desplazamiento de lo particular a lo universal que caracteriza al objeto a con la Cosa (la Madre, en tanto prohibida) resulta "idéntica" al modo de desplazamiento (tendencial) particular-universal del significante vacío en la operación hegemónica. Al igual que el significante vacío en la operación hegemónica, el objeto a representa una forma particular, pero asume simbólicamente el rol de universalidad. Esta universalización es ilusoria, en tanto supone el sueño de encarnar una "totalidad mítica" madre/hijo (el acceso imposible a la Madre-Cosa), o su correlato político, el sueño de la sociedad "reconciliada consigo misma" (Laclau, 2005: 148-149). Según Laclau (2005: 148): "Con esto logramos una explicación completa de lo que significa una investidura radical. El hacer de un objeto la encarnación de una plenitud mítica. El afecto (es decir, el goce) constituye la esencia misma de la investidura" (el subrayado es mío).

Del mismo modo, en Debates y combates, Laclau (2008) retoma la homología de LRP entre el desplazamiento tendencial del significante vacío en la relación hegemónica y el objeto parcial elevado a la "dignidad de la Cosa" de la teoría lacaniana:

He intentado mostrar en La razón populista cómo la lógica de la hegemonía y la del objeto a se superponen en buena medida y se refieren ambas a una relación ontológica 
fundamental, en la cual lo pleno (fullness) sólo puede ser tocado a través de un investimiento en un objeto parcial; que no es una parcialidad dentro de la totalidad, sino una parcialidad que es la totalidad [...]. El punto relevante para nuestro tema es que lo pleno -la Cosa freudiana- es inalcalzable; es tan sólo una ilusión retrospectiva que es sustituida por objetos parciales que encarnan esa totalidad imposible. En palabras de Lacan: la sublimación consiste en elevar un objeto a la dignidad de la Cosa. Como he intentado mostrar, la relación hegemónica reproduce todos esos momentos estructurales: una cierta particularidad asume la representación de una universalidad que siempre se aleja (Laclau, 2008: 20; el subrayado y las negritas son míos).

En sus últimos trabajos, Laclau nuevamente replicó esta homología entre la lógica de desplazamiento (tendencial) de la hegemonía y la lógica del objeto a:

Este proceso por el cual las identidades dejan de ser puramente inmanentes a un sistema y requieren una identificación con un punto trascendente a este sistema -que es lo mismo que decir: cuando una particularidad se convierte en el nombre de una universalidad ausente- es lo que llamamos hegemonía. Su lógica es idéntica a la del objeto a (Laclau, 2014: 86; el subrayado es mío).

Más allá de si esta homología es lograda, ${ }^{5}$ en la perspectiva de Laclau es utilizada para mostrar que la dinámica de desplazamiento de lo particular hacia lo universal nunca deja de representar una particularidad. De este modo, sólo fantasmáticamente un elemento particular puede suponer el acceso a una universalidad plena.

La relevancia que adquieren estas especificaciones para el Análisis Político del Discurso (APD) radica en que permiten complejizar cierta interpretación simplificada de la relación entre el líder político y sus adherentes, en clave lacaniana. Esta interpretación reduccionista ignora la existencia de otras formas posibles de identificación social que van más allá del vínculo hipnótico Líder-Padre/masa, tal como fueron planteadas inicialmente por Lacan (1961-1962, 2006y 2008) y recuperadas por el propio Laclau.

De hecho, hemos hallado un poco conocido pasaje en LRP, en el cual Laclau refiere a la posibilidad que el discurso de la publicidad de mercancías como Marlboro o Coca Cola, funcionen como "puntos de fijación nodal" y, de este modo, adopten, imaginariamente, la representación de una universalidad inconmensurable:

5 En este sentido, Ramírez (2012) se refiere al exceso del orden de lo Real que para Lacan caracteriza al objeto a. Sin embargo, en LRP, el mismo Laclau (2005) destaca este "exceso" constitutivo en el campo de la representación, a partir de la existencia al mismo tiempo externa e interna a lo simbólico de un "Real heterogéneo" que lo interrumpe, asimilado a la noción de Lumpenproletariado de Marx. Al respecto, véase Barros (2009). 
Hemos sostenido que la totalización del campo popular -la cristalización discursiva del momento de plenitud/vacío- sólo puede tener lugar si un contenido parcial adopta la representación de una universalidad que es inconmensurable con él [...]. Marlboro y Coca-Cola pueden funcionar como puntos de fijación nodal dentro de las imágenes de la publicidad y, así, ser los significantes de una cierta totalización, pero aun son las entidades particulares, Marlboro y Coca-Cola, las que desempeñan ese rol (Laclau, 2005: 137; el subrayado y las negritas son míos).

Como se puede apreciar, en el ejemplo del discurso de la publicidad no está presente el líder populista como fuente de identificación, sino que son las imágenes de las mercancías las que se constituyen como puntos nodales.

\section{El papel de las demandas en la identificación populista}

Otra de las innovaciones que plantea Laclau en LRP, en clave lacaniana, es el énfasis en el papel de la demanda en la construcción discursiva del lazo social. En este trabajo, Laclau afirma que el análisis del populismo debe partir de la noción de demanda como unidad mínima de análisis político: ${ }^{6}$

Si queremos determinar las especificaciones de una práctica articulatoria populista, debemos identificar unidades más pequeñas que el grupo para establecer el tipo de unidad al que el populismo da lugar. La unidad más pequeña por la cual comenzaremos corresponde a la categoría de demanda social (Laclau, 2005: 98).

Según Laclau, para que haya populismo, las demandas aisladas (definidas como demandas "democráticas") deben ingresar en una relación de equivalencia entre sí (definidas como demandas "populares”) y construir una frontera discursiva que tienda a dividir el espacio social en dos campos dicotómicos: el "pueblo" (en el sentido de "los de abajo") y el "poder" (Laclau, 2005: 98-99 y ss.).

Lo que nos interesa destacar es el uso que hace Laclau de la noción de demanda para analizar el afecto en las identidades populares. Vimos que Laclau enfatiza en el rol ontológico del objeto a. Según Laclau (2005: 152), "los objetos a presuponen catexias diferenciadas, y es a estas catexias que denominamos afecto". En este punto, Laclau plantea una "secuencia estructural"

6 Esta concepción de la demanda como unidad mínima para el análisis político generó algunas críticas en la bibliografía especializada, ya que parece presuponer una demanda previa al sujeto (De Ípola, 2009), no distingue entre los conceptos de demanda y necesidad (Gutiérrez Vera, 2011) y deja a un lado su producción histórica y social, es decir, las luchas por dar sentido a determinadas situaciones y relaciones sociales, que a su vez dependen de experiencias previas parcialmente sedimentadas (Retamozo, 2017 y 2021). 
fundamental para “enfocar correctamente la cuestión de las identidades populares”. Veamos:

En primer lugar, tenemos el momento de la plenitud mítica que buscamos en vano: la restauración de la unidad madre/hijo, en términos políticos, la sociedad completamente reconciliada. Luego tenemos la parcialización de las pulsiones: la pluralidad de objetos a que, en algún punto, encarnan la plenitud en última instancia inalcanzable (Laclau, 2005: 152).

Sin embargo, la encarnación de la plenitud ausente requiere de una entidad encarnadora para adquirir una investidura catexial:

Encarnar algo sólo puede significar dar un nombre a lo que está siendo encarnado; pero como lo que está siendo encarnado es una plenitud imposible, algo que carece de una consistencia independiente propia, la entidad encarnadora se convierte en el objeto pleno de investidura catéctica (Laclau, 2005: 152).

Aquí Laclau nuevamente realiza una homología con conceptos lacanianos en clave de análisis político. Pero, esta vez, la homología se establece entre el objeto parcial que es elevado a la dignidad de la Cosa, y el desplazamiento metonímico de la demanda democrática a la demanda popular y su conversión en un punto nodal de sublimación que adquiere valor de pecho, en la operación hegemónica:

En términos psicoanalíticos: mientras el deseo no encuentra satisfacción y vive solo mediante su reproducción a través de una sucesión de objetos, la pulsión puede hallar satisfacción, pero esto sólo se logra mediante la sublimación del objeto, elevándolo a la dignidad de la Cosa. Vamos a traducir esto al lenguaje político: una determinada demanda, que tal vez al comienzo era sólo una más entre muchas, adquiere en cierto momento una centralidad inesperada y se vuelve el nombre de algo que la excede, de algo que no puede controlar por sí misma y que no obstante se convierte en un destino al que no se puede escapar. Cuando una demanda democrática ha atravesado esta senda, se convierte en una demanda popular. Pero es inalcanzable en términos de su propia particularidad inicial, material; debe convertirse en un punto nodal de sublimación; debe adquirir un valor de pecho. Es sólo entonces que el nombre se separa del concepto, el significado del significante. Sin esta separación no habría populismo (Laclau, 2005: 153; el subrayado y las negritas son míos).

Como se puede apreciar, en esta última cita Laclau se centra en la demanda como un objeto parcial fuente de identificación, descentrando a la figura del líder.

El propio Laclau ilustra con algunos ejemplos históricos. Uno de ellos es la demanda de Solidaridad en Polonia (Laclau, 2005). Como lo sintetiza en un artículo publicado en 2006, en la revista Cuadernos del Cendes: 
Tomemos un ejemplo que usé en varios puntos de La razón populista: Solidarnosc (Solidaridad) en Polonia. Esta era una sociedad donde una pluralidad de demandas frustradas por un régimen opresor había creado una equivalencia espontánea entre ellas que, sin embargo, era necesario expresar a través de algún tipo de unidad simbólica [...]. [En ese marco] Las demandas de Solidaridad se convertirán en el símbolo de una cadena más amplia de demandas cuya inestable equivalencia en torno a ese símbolo va a constituir una identidad popular más amplia (Laclau, 2006b, s/p).

En este ejemplo es una demanda particular, Solidaridad, la que condensó a una amplia cadena de equivalencias y se constituyó en la dinámica política en el punto nodal de identificación simbólica del grupo.

\section{Las oscilaciones de la teoría discursiva del populismo de Laclau}

Vimos que, en el capítulo inicial de LRP, Laclau plantea dos modos extremos de identificación social y luego incorpora un continuum gradual de opciones intermedias, a partir del concepto mediador de objeto a. Pero hay un problema en este esquema, ya que, como observamos, en diversos fragmentos de LRP (y de sus textos posteriores), Laclau sitúa al objeto a como homólogo al desplazamiento particular-universal del significante vacío en la operación hegemónica y como un elemento ontológico para comprender las identificaciones populares. De este modo, al igual que en sus trabajos de etapas previas, la figura individual del líder queda excluida del esquema, sustituyendo al significante vacío por el objeto pequeño a de Lacan.

De hecho, en un fragmento de LRP el propio Laclau sostiene: “No hay populismo sin una investidura afectiva en un objeto parcial" (Laclau, 2005: 149). Pero luego vincula a los objetos parciales con "objetivos, figuras, símbolos" que "son investidos de tal manera que se convierten en los nombres de su ausencia" ${ }^{7}$ (Laclau, 2005: 149). En este caso, Laclau oscila entre la identificación con determinadas "figuras" (como puede ser el líder) y la identificación con ciertos "objetivos" o "símbolos" (ideas, valores colectivos) que (como el pecho y la madre) median entre la parte y el todo. El problema aquí es que Laclau confunde al significante primordial que adquiere el "valor de pecho" con el pecho mismo, esto es, el objeto de deseo primordial con el objeto (pulsionar) investido como objeto a-causa-de-deseo. Esto contrasta con los aportes sobre el papel discursivo de la demanda (en tanto concepto diferente al de necesidad primaria) que vimos anteriormente.

7 Todos estos subrayados son míos. 
Por otra parte, en la lectura habitual del esquema laclauiano parecería que la ligazón catexial sólo tiene lugar en los discursos populistas. Sin embargo, en LRP Laclau destaca la importancia general del afecto y de la ligazón catexial en la construcción de hegemonías, más allá de los procesos populistas. En sus palabras:

Los complejos que denominamos formaciones discursivas o hegemónicas, que articulan las lógicas de la diferencia y de la equivalencia, serían ininteligibles sin el componente afectivo [...]. De esta manera, podemos concluir que cualquier totalidad social es resultado de una articulación indisociable entre la dimensión de significación y la dimensión afectiva (Laclau, 2005: 143; el subrayado es mío).

Estas consideraciones invitan a suponer que la dimensión afectiva, al ser constitutiva, también se encuentra presente en las identidades "institucionalistas" o "administrativistas", es decir, en aquellas en las que prevalece la satisfacción diferencial y gestionaria de las demandas (Laclau, 2005: 107). Laclau menciona como un ejemplo de este tipo de discurso administrativista la frase de Saint Simon de pasar del gobierno de los hombres a la administración de las cosas. El análisis de este tipo de discursos políticos gestionarios contribuye, además, a evitar el habitual problema de la "reificación" del populismo como única forma posible de la política y su contraposición estricta al "antipopulismo" (De Cleen y Glynos, 2021: 3-4 y ss.). De este modo, el análisis del afecto y las ligazones catexiales puede abordarse en fenómenos y procesos sociopolíticos no necesariamente catalogados de populistas.

\section{Contribuciones para analizar las identificaciones en la dinámica política desde la teoría del discurso: tres modos de identificación social}

A partir de la distinción analítica que propone Laclau en LRP entre el ejemplo extremo de la identificación directa con el líder y el ejemplo extremo opuesto de la identificación con la organización, los aportes sobre la centralidad ontológica del objeto a como concepto mediador y el descentramiento de la figura narcisística del líder, proponemos a continuación una tipología con tres modalidades de identificación social para el estudio de la operación hegemónica:

La identificación directa con la figura del líder político: la identificación se establece casi hipnóticamente en torno al líder popular como Significante Amo (S1), cuya figura condensa y representa simbólicamente a múltiples significados, demandas y sujetos sociales, y otorga una cohesión imaginaria a determinado grupo u organización. Por ejemplo, la figura de 
Perón cuando retornó del exilio en 1973, tal como fue analizada por Sigal y Verón (2003).

La identificación indirecta en torno al líder mediada a partir de un objeto parcial que se convierte en significante vacío y ocupa el rol de punto nodal: la identificación se establece mediada por ciertos rasgos particulares, demandas, valores, mandatos, principios o ideales compartidos por determinado grupo, organización o comunidad, que exceden a la figura del líder y encarnan la plenitud social. Por ejemplo, la identificación popular con la demanda de Solidaridad en Polonia que analizó Laclau (2005 y 2006b), que luego se condensó en la figura de Walesa. En esta línea, Muñoz (2016) analizó el proceso por el cual el movimiento indígena-campesino en Bolivia asumió la demanda "Por el agua y la vida digna". Esta demanda particular luego devino en plataforma de inscripción de otras demandas sociales, frente al saqueo de los recursos naturales de la Nación y como recuperación de la soberanía de los pueblos y, de este modo, se convirtió en un significante vacío. Finalmente, los sindicatos cocaleros y campesinos se articularon políticamente como pueblo y devinieron en Estado a través de su identificación y adhesión a la figura de Evo Morales.

La identificación con ciertos valores o ideas compartidas por el grupo u organización que funcionan como objetos a causa de deseo: la identificación se establece en torno a ciertos objetos parciales (valores, principios, demandas o ideas compartidas por cierto grupo, comunidad u organización social) que funcionan como objetos a y se invisten como causa de deseo, al llenar imaginariamente la falta. Por ejemplo, la función de fijación nodal de las imágenes de la publicidad de Marlboro o de Coca-Cola que menciona Laclau (2005). En esta línea, Stavrakakis (2010: 255-283) analizó los discursos de la publicidad y sus mandatos consumistas en el capitalismo actual como un objeto a causa de deseo que promete eliminar la falta y se inviste de goce. Por su parte, Martínez (2018) encontró en el grito: “iNi Una Menos!” un contenido particular que logró articular a una multiplicidad de demandas sociales y se convirtió en punto nodal de identificación popular del movimiento feminista, en la Argentina actual.

Al desplazarse al estudio de procesos sociopolíticos concretos, pueden presentarse variaciones históricas en los modos e intensidades de identificación, que incluyen desde una lógica de creciente institucionalización y sedimentación de los objetos parciales, hasta su total desestructuración. Un ejemplo de ello es el caso de la estabilidad económica que garantizó la Convertibilidad en la Argentina. En condiciones de control inflacionario, expansión económica y auge del crédito popular, la estabilidad del " 1 a 1 " se 
convirtió a partir de 1991 en un punto de fijación nodal y resultó clave para generar identificaciones populares, afianzar el orden neoliberal y reelegir en primera vuelta al líder peronista Carlos Menem en 1995. En 1999, con la elección presidencial del dirigente radical Fernando De la Rúa, el sistema de Convertibilidad fortaleció su grado de institucionalización, perdurando más allá de sus gestores de diferentes colores políticos, hasta su derrumbe en diciembre de 2001 (Fair, 2008, 2019c).

\section{Herramientas metodológicas para investigar las identificaciones sociales desde la Teoría Política del Discurso}

Existen diferentes alternativas para analizar las identificaciones sociales desde la Teoría Política del Discurso (TPD). Estas opciones no pueden establecerse a priori ni de un modo taxativo, ya que dependen del tema escogido, los objetivos, preguntas e hipótesis de cada investigación. De todos modos, para evitar caer en el peligro del "todo vale" que mencionan Howarth y Glynos (2007), se pueden plantear algunas pautas y lineamientos metodológicos básicos (aunque contingentes), en consonancia con los presupuestos onto-epistemológicos que definen a la teoría laclauiana de la hegemonía (sobredeterminación discursiva, contingencia e historicidad radical y negatividad constitutiva), el uso witgensteiniano de la teoría como una "caja de herramientas" y la centralidad del concepto de articulación (Buenfil Burgos, 2019).

Tomando en cuenta que para la TPD las identificaciones se construyen en el marco de una "relativa estructuralidad en la que emergen esos procesos" (Barros, 2013: 45), un punto de partida para el análisis político-discursivo radica en la importancia de contextualizar e historizar adecuadamente al objeto de estudio. Como señala Laclau (2005: 14), la identificación de cuáles son los significantes "privilegiados" que condensan el campo de significación presupone una "historia contextual". En este sentido, para analizar un fenómeno de identificación social reciente, además del estudio de la coyuntura específica, se deben considerar ciertas transformaciones histórico-discursivas parcialmente estructuradas en el tiempo. Entre ellas, el capitalismo neoliberal, la mundialización económica (conocida como globalización), la expansión de los medios de comunicación y las tecnologías electrónicas, la crisis de representatividad política y el crecimiento de los nuevos movimientos sociales, con sus efectos de creciente mercantilización de lo social, mediatización de lo político, interconexión planetaria, individualización y fragmentación de la estructura social y de las identidades y segregación espacial, en paralelo 
con nuevas formas emergentes de socialización política, organización popular y vinculación colectiva. El uso de bibliografía especializada permite conceptualizar estos fenómenos históricos parcialmente sedimentados.

También se pueden utilizar herramientas teóricas complementarias. Por ejemplo, a partir de la tesis lacaniana del declive de la imagen paterna, y su posterior denuncia del fraude de la autoridad paterna de Freud (Lacan, 2006 y 2008), que condujo a Lacan a destacar que el padre es un significante más (Laurent, 1992), se pueden estudiar las transformaciones en las formas tradicionales (paternalistas) de ejercer la autoridad y fenómenos como la crisis de representatividad política de los líderes. Este cuestionamiento al poder patriarcal se potencia con los avances recientes del rol de la mujer y los movimientos de liberación feministas, pero también con los desplazamientos del Discurso Capitalista Neoliberal (Fair, 2019c) y el llamado orden posmoderno. Estas transformaciones históricas promueven un modo de estructuración del lazo social menos conservador y más liberal que la moral victoriana y restrictiva de la época de Freud, que se centraba en el estricto deber y las fuertes restricciones superyoicas. En las nuevas circunstancias históricas, los objetosfetiches mercantiles difundidos como imperativos sociales por el Discurso Capitalista pueden ser entendidos como objetos petit a que, en ausencia imaginaria de la castración fálica, se invisten catexialmente a partir de su promesa de llenar la falta (Lacan, 2006; Stavrakakis, 2007 y 2010).

Por otro lado, la concepción lacaniana de la demanda como un deseo de reconocimiento (Rabinovich, 2003), y su relación con el goce (jouissance), permite abordar desde el discurso la percepción subjetiva de reconocimiento social de los "sin parte" (Rancière, 1996) hacia ciertas demandas privilegiadas atribuidas a los liderazgos populares y contribuye a comprender el afecto libidinal investido en los líderes o lideresas. Ello a partir del análisis de sus interpelaciones, sus gestos simbólicos y sus políticas públicas de reparación histórica del daño, dignificación y reconocimiento igualitario (Barros, 2009 y 2013; Aibar, 2013).

Como señala Martín Retamozo (2009), la centralidad que adquiere el concepto de demanda en la teoría laclauiana también resulta clave para analizar los procesos de identificación desde la voz de los movimientos sociales, en el momento en que éstos construyen demandas sociales que parten de una "falta" y se presentan en el espacio público mediante acciones colectivas que sostienen en el tiempo e implican procesos identitarios. Desde la TPD, el análisis de las demandas no puede pensarse independientemente del lenguaje, ya que este inscribe una situación como una demanda-deseo (Retamozo, 2009). Al mismo tiempo, presupone el estudio de sus condiciones sociales 
de producción, lo cual implica indagar en la historicidad de las demandas y su parcial sedimentación, sus modos de organización y acción colectiva, y las disputas simbólicas por dar sentido a determinadas situaciones y estructurar determinadas relaciones sociales (Retamozo, 2021).

La concepción lacaniana de la demanda como deseo de reconocimiento, junto con la noción de "robo de goce" (Žižek, 1992; Stavrakakis, 2010), también puede contribuir a analizar las formas recientes de identificación social en torno a los liderazgos de derechas, lo que incluye tanto a los discursos autoritarios, reaccionarios y fundamentalistas (populismos de derecha), como a los discursos tecnocrático-gerenciales (administrativistas). Estos discursos políticos emergentes pueden ser entendidos como diferentes variantes ideológicas que asume el Discurso Amo en el capitalismo actual, que generan formas de identificación social a través de la esencialización y estigmatización de la alteridad y la construcción de chivos expiatorios (el homosexual, la mujer empoderada, el empleado público, el judío, el inmigrante, el extranjero, el pobre) que expresan el odio profundo al goce del Otro (Fair, 2021). Por ejemplo, Lindsay Pérez Huber (2016) encontró en Donald Trump un discurso racista-nativista que (re)producía percepciones dominantes sedimentadas sobre el inmigrante latino indocumentado, la gente de color y el terrorismo islámico como "invasores" y "criminales peligrosos" que amenazaban el estilo de vida americano, para justificar su exclusión social, explicar la crisis económica y hacer de nuevo a Estados Unidos grande (Make America great again!).

En relación con las técnicas de investigación para analizar las identificaciones sociales en la dinámica de la operación hegemónica, las mismas deberían centrarse en técnicas cualitativas, ya que permiten abordar los componentes afectivos a través de la palabra (Boito, Gandía y Scribano, 2008: 230). Entre las diferentes técnicas que pueden utilizarse desde la TPD se encuentran: análisis de discursos presidenciales oficiales, entrevistas semiestructuradas, grupos focales o de discusión, observación participante, archivos de prensa y otros documentos y análisis de contenido de redes sociales. También es posible combinar diversas técnicas cualitativas. Por ejemplo, Schuttenberg (2013) reconstruyó las trayectorias históricas y analizó las formas de identificación política del Movimiento Evita, el Movimiento Libres del Sur y el Movimiento de Unidad Popular (Argentina), a partir de documentos y entrevistas semiestructuradas a dirigentes de las tres organizaciones. Las entrevistas y el análisis documental le permitieron al autor identificar los núcleos donde se sedimentaron históricamente los sentidos de sus identidades "nacional-populares" durante las etapas previas a 2003, y cómo se resignificaron en el contexto del gobierno de Kirchner (Schuttenberg, 2013). 
En cuanto a las estrategias metodológicas, el investigador del discurso puede centrarse en la dimensión de la Construcción hegemónica y examinar situacionalmente las interpelaciones que construyen determinados actores de poder de elevada fuerza performativa (por ejemplo, el Presidente o Presidenta), con el objeto de generar identificaciones o afianzar vínculos sociales (Fair, 2021). Una opción útil consiste en vincular las interpelaciones presidenciales con las estrategias de legitimación de sus principales políticas de gobierno.

Otra opción útil para analizar la construcción de identificaciones políticas se relaciona con el estudio de las marcas de afectividad en los textos. Desde los aportes de la lingüística a los estudios del discurso, Adriana Bolívar (2016) distingue diferentes tipos de afectividad en el discurso político: declarada, cuando el político dice lo que siente (por ejemplo, me siento/estoy/ muy emocionado); implicada o indirecta, cuando da a entender lo que siente, como muestras de preocupación o amor; narrada, cuando cuenta sus experiencias de vida; inducida, cuando con sus palabras el líder genera emociones de esperanza o de miedo (a partir de promesas o amenazas); evocada, cuando sus palabras aluden a una historia compartida (nosotros somos los hijos de Bolívar, somos guerreros); e imaginada, cuando se presenta un mundo hipotético futuro (si ellos ganan van a desestabilizar). A través de un análisis interaccional (relacional) y contextualizado, se puede identificar un continuum de intensidades de afectividad positiva en los textos (Bolívar, 2016).

El analista del discurso político también puede centrarse en la dimensión de la Eficacia hegemónica, para estudiar los efectos performativos de las interpelaciones dominantes sobre determinados agentes situados en el rol de interpelados (por ejemplo, el impacto del discurso presidencial en referentes de movimientos sociales). En esta línea, el investigador puede analizar las metáforas, las metonimias, las sinécdoques y las catacresis -así como los adjetivos de valencia positiva- que los agentes interpelados construyen para expresar sentimientos de apego o ligazón afectiva en torno a determinadas ideas, demandas, valores y/o figuras de autoridad política (Fair, 2021). A partir de allí, debería detectar en los textos las cadenas significantes clave y los puntos nodales que condensan las identificaciones sociales, desde un análisis relacional. Para una investigación situada en América Latina, otro indicador relevante es el resultado de las votaciones populares, principalmente las elecciones presidenciales.

Para el análisis específico de las identificaciones en torno a los objetos parciales, el analista del discurso puede centrarse en las cadenas de equivalencias 
adosadas a ciertos significantes clave que se invisten en la dinámica política como objetos a causa de deseo, al llenar imaginariamente la falta y suturar el orden comunitario. Para ponderar las identificaciones sociales desde el discurso político, el investigador puede elaborar una escala cualitativa de categorías escalares de oposición gradual, que se basan en una relación de gradualidades entre un término medio, por un lado, y su grado de rebasamiento (hacia un más o un menos), por el otro (Ducrot y Todorov, 1981). Luego puede atribuir, a través de un continuum descendente de intensidades, grados diferenciales de ligazón afectiva entre los actores interpelados.

Por último, es importante destacar que desde los presupuestos ontoepistemológicos de la Teoría Política del Discurso, el estudio de estos modos de identificación es siempre producto de un abordaje interpretativo y atributivo por parte del analista.

\section{Conclusiones}

En este trabajo analizamos la cuestión de las identificaciones en la teoría de la hegemonía de Laclau, centrándonos en los cruces entre el líder y la función del objeto a de Lacan en la teoría del populismo. A través de una pormenorizada lectura de La razón populista, elaboramos una tipología innovadora con tres modos de identificación social para el análisis discursivo de la operación hegemónica: la identificación directa con la figura del líder político; la identificación indirecta con el líder mediada a partir de ciertos objetos parciales que se convierten en significantes vacíos y ocupan el rol de puntos nodales; y la identificación con una demanda, ideal o valor compartido por el grupo u organización que funciona como objeto a causa de deseo.

En el primer caso, la identificación se establece casi hipnóticamente en torno al líder, cuya figura condensa y representa múltiples significados y sujetos sociales. En el segundo caso, la identificación se establece de un modo indirecto y mediado a partir de ciertas ideas o valores colectivos, demandas sociales o rasgos específicos que exceden a la figura del líder y encarnan la plenitud social. En el tercer caso, la identificación se establece con ciertos objetos parciales (valores, principios, demandas o ideas compartidas por el grupo, comunidad u organización social) que funcionan como objetos a y se invisten como causa de deseo. Al desplazarse al estudio de procesos políticos y sociales concretos, destacamos que pueden presentarse diversas variaciones históricas en los modos e intensidades graduales de identificación, que incluyen desde una lógica de creciente institucionalización y sedimentación, hasta su total desestructuración. 
En la parte final del artículo, desplegamos algunas herramientas teóricometodológicas útiles para investigar los procesos de identificación social en la dinámica política, a través de un análisis contextualizado, interpretativo y atributivo. A partir del despliegue de esta propuesta analítica, procuramos contribuir a profundizar y fortalecer el análisis discursivo de identidades y procesos sociopolíticos contemporáneos, desde la teoría de la hegemonía.

\section{Referencias}

Aboy Carlés, Gerardo (2005), "Populismo y democracia en la Argentina contemporánea. Entre el hegemonismo y la refundación", en Estudios Sociales, vol. 28, Argentina: Universidad del Litoral.

Aibar, Julio (2013), "La miopía del procedimentalismo y la presentación populista del daño", en Aibar, Julio [coord.], Vox populi. Populismo y democracia en Latinoamérica, México: Universidad Nacional de General Sarmiento, Universidad Nacional de Avellaneda y Facultad Latinoamericana de Ciencias Sociales.

Arditi, Benjamin (2010), "Politics is hegemony is populism?", en Constellations, vol. 17, núm. 3, Estados Unidos: Blackwell Publishing Ltd.

Barros, Sebastián (2009), "Salir del fondo del escenario social: sobre la heterogeneidad y la especificidad del populismo", en Pensamento Plural, vol. 5, Brasil: Universidad Federal de Pelotas.

Barros, Sebastián (2013), "Despejando la espesura. La distinción entre identificaciones populares y articulaciones políticas populistas", en Aboy Carlés, Gerardo, Barros, Sebastián y Melo, Julián, Las brechas del pueblo. Reflexiones sobre identidades populares y populismo, Argentina: Universidad Nacional de General Sarmiento y Universidad Nacional de Avellaneda.

Barros, Sebastián (2018), "Polarización y pluralismo en la teoría de la hegemonía de Ernesto Laclau", en Latinoamérica. Revista de Estudios Latinoamericanos, núm. 67, México: Universidad Nacional Autónoma de México.

Boito, María Eugenia, Gandía, Claudia y Scribano, Adrián (2008), "Psicoanálisis, psicología e investigación social cualitativa”, en Scribano, Adrián, El proceso de investigación social cualitativo, Argentina: Prometeo.

Bolívar, Adriana (2016), "El discurso de la afectividad en la interacción política”, en Bañón Hernández, Antonio Miguel et al. [eds.], Oralidad y análisis del discurso, España: Editorial Universitaria de Almería.

Buenfil Burgos, Rosa Nidia (2019), Ernesto Laclau y la investigación educativa en Latinoamérica: implicaciones y apropiaciones del Análisis Politico del Discurso, Argentina: Consejo Latinoamericano de Ciencias Sociales.

Castagnola, Gustavo (2000), Body of Evidence. Juan Domingo Perón's Discourse during his Political Exile (1955-1972), Reino Unido: University of Essex.

Copjec, Joan (1995), “Sex and the euthanasia of reason", en Read my desire, Estados Unidos: Massachusetts Institute of Technology Press.

Copjec, Joan (2003), Imagine there's no Woman: Ethics and Sublimation, Estados Unidos: Massachusetts Institute of Technology Press. 
De Cleen, Benjamin y Glynos, Jason (2021), "Beyond Populism Studies”, en Journal of Language and Politics, vol. 20, núm. 1, Holanda: John Benjamins Publishing.

De Ípola, Emilio (2009), "La última utopía. Reflexiones sobre la teoría del populismo de Ernesto Laclau”, en Hilb, Claudia [comp.], El politico y el cientifico. Ensayos en homenaje a Juan Carlos Portantiero, Argentina: Siglo XXI.

Ducrot, Oswald y Todorov, Tzvetan (1981), Diccionario enciclopédico de las ciencias del lenguaje, Argentina: Siglo XXI.

Fair, Hernán (2008), "La función del significante convertibilidad en la articulación discursiva de la identidad menemista”, en Question, Revista de la Facultad de Periodismo y Comunicación Social, núm. 17, Argentina: Universidad Nacional de La Plata.

Fair, Hernán (2019a), "Psicoanálisis lacaniano, retórica y teoría gramsciana: tres homologías de la hegemonía y sus usos ónticos en la dinámica política en la Teoría del Discurso de Laclau", en Revista Brasileira de Estudos Politicos, núm. 119, Brasil: Universidad Federal de Minas Gerais.

Fair, Hernán (2019b), "La hegemonía en su mutuo anudamiento óntico-ontológico en la teoría política de Ernesto Laclau”, en Trans/form/ação, vol. 42, núm. 2, Brasil: Universidad Estadual Paulista.

Fair, Hernán (2019c), "El Discurso Capitalista Neoliberal desde una perspectiva lacaniana”, en Desafíos, núm. 31, Colombia: Universidad Nacional de Colombia.

Fair, Hernán (2021), “Fantasías, mitos y creencias ideológicas en los tiempos de Macri”, en InterSedes, vol. 22, núm. 45, Costa Rica: Universidad de Costa Rica.

Freud, Sigmund (1973), "Psicología de las masas y análisis del yo", en Obras completas de Sigmund Freud, tomo 3, España: Biblioteca Nueva.

Glynos, Jason y Howarth, David (2007), Logics of critical explanation in social and political theory, Reino Unido: Routledge.

Gutiérrez Vera, Daniel (2011), “Ernesto Laclau: el populismo y sus avatares”, en Íconos, núm. 40, Ecuador: Facultad Latinoamericana de Ciencias Sociales.

Ipar, María Cecilia (2020), "La dimensión del afecto y la influencia del psicoanálisis en la conceptualización del populismo de Laclau”, en Revista Brasileira de Ciencia Politica, núm. 33, Brasil: Universidad de Brasilia.

Lacan, Jacques (1961-1962), Seminario 9: La identificación, Argentina: Versión íntegra.

Lacan, Jacques (1987), Seminario 11: Los cuatro conceptos fundamentales del psicoanálisis, Argentina: Paidós.

Lacan, Jacques (1990), Seminario 7: La ética del psicoanálisis, Argentina: Paidós.

Lacan, Jacques (2006), Seminario 17: El reverso del psicoanálisis, Argentina: Paidós.

Lacan, Jacques (2008), Seminario 20: Aún, Argentina: Paidós.

Laclau, Ernesto (1993), Nuevas reflexiones sobre la revolución de nuestro tiempo, Argentina: Nueva visión.

Laclau, Ernesto (1998), “Deconstrucción, pragmatismo, hegemonía”, en Mouffe, Chantal [comp.], Deconstrucción y pragmatismo, Argentina: Espacios del saber.

Laclau, Ernesto (2003), "Identidad y hegemonía: el rol de la universalidad en la constitución de lógicas políticas”, en Butler, Judith, Laclau, Ernesto y Žižek, Slavoj [comps.], Contingencia, hegemonía, universalidad, México: Fondo de Cultura Económica.

Laclau, Ernesto (2005), La razón populista, Argentina: Fondo de Cultura Económica.

Laclau, Ernesto (2006a), "La deriva populista y la centroizquierda latinoamericana”, en Nueva Sociedad, núm. 205, Argentina: Friedrich Ebert Stiftung. 
Convergencia Revista de Ciencias Sociales, vol. 29, 2022, Universidad Autónoma del Estado de México

Laclau, Ernesto (2006b), “ ¿Por qué construir un pueblo es la tarea principal de la política radical?”, en Cuadernos del Cendes, vol. 23, núm. 62, Venezuela: Universidad Central de Venezuela.

Laclau, Ernesto (2008), Debates y combates, Argentina: Fondo de Cultura Económica.

Laclau, Ernesto (2014), Los fundamentos retóricos de la sociedad, Argentina: Fondo de Cultura Económica.

Laclau, Ernesto y Zac, Lilian (2002), "Cuidado con el vacío: el sujeto de la política”, en Buenfil Burgos, Rosa [comp.], Configuraciones discursivas en el campo educativo, México: Plaza y Valdés.

Laurent, Eric (1992), Lacan y los discursos, Argentina: Manantial.

Martínez, Natalia (2018), “ ¿Pueblo feminista? Algunas reflexiones en torno al devenir popular de los feminismos", en Latinoamérica. Revista de Estudios Latinoamericanos, núm. 67, México: Universidad Nacional Autónoma de México.

Merlin, Nora (2015), "La demanda populista y el líder", en Studia Politicae, vol. 31, Argentina: Universidad Católica de Córdoba.

Muñoz, María Antonia (2016), "Sujeto político, democracia y pueblo: Argentina y Bolivia frente al nuevo siglo”, en Entramado, vol. 12, núm. 2, Colombia: Unilibre.

Pérez Huber, Lindsay (2016), "Make America Great Again! Donald Trump racist nativism and the virulent adherence to white supremacy amid U.S. demographic change", en Charleston Law Review, vol. 10, Estados Unidos: Charleston School of Law.

Rabinovich, Diana (2003), El concepto de objeto en la teoría psicoanalitica, Argentina: Manantial.

Ramírez, Fernando (2012), "Crítica de la razón populista”, en Acheronta, Revista de Psicoanálisis y Cultura, núm. 27, Argentina: Acheronta.

Rancière, Jacques (1996), El desacuerdo. Politica y Filosofía, Argentina: Nueva visión.

Retamozo, Martín (2009), "Las demandas sociales y el estudio de los movimientos sociales", en Cinta de Moebio, vol. 35, Chile: Universidad de Chile.

Retamozo, Martín (2017), "La teoría del populismo de Laclau: usos y controversias en América Latina en la perspectiva posfundacional", en Revista de Estudios Latinoamericanos, vol. 64, México: Universidad Nacional Autónoma de México.

Retamozo, Martín (2021), "Hegemonía, subjetividad y sujeto: notas para un debate a partir del posmarxismo de Ernesto Laclau”, en Novos Olhares Sociais, vol. 4, Brasil: Universidade Federal do Recôncavo da Bahia.

Schuttenberg, Mauricio (2013), "Calibrando los lentes teóricos. Operacionalización y estrategias metodológicas para el análisis de las identidades nacional populares”, en Polis, núm. 35, Chile: Universidad de Los Lagos.

Sigal, Silvia y Verón, Eliseo (2003), Perón o muerte: Los fundamentos discursivos del fenómeno peronista, Argentina: Legasa.

Sosa, Martina (2011), "Sujetos políticos y dimensión afectiva: una lectura de La razón populista de Ernesto Laclau”, en International Journal of Žižek Studies, vol. 5, núm. 1, Reino Unido: University of Leeds.

Stavrakakis, Yannis (2007), Lacan y lo politico, Argentina: Prometeo-Universidad Nacional de La Plata.

Stavrakakis, Yannis (2010), La izquierda lacaniana. Psicoanálisis, teoría, politica, Argentina: Fondo de Cultura Económica.

Žižek, Slavoj (1992), El sublime objeto de la ideología, Argentina: Siglo XXI. 
Hernán Fair. Doctor en Ciencias Sociales por la Universidad de Buenos Aires. Actualmente trabaja como Investigador Adjunto del Consejo Nacional de Investigaciones Científicas y Técnicas (CONICET) con sede en el Instituto de Economía y Sociedad en la Argentina Contemporánea (IESAC) de la Universidad Nacional de Quilmes. Profesor en el Departamento de Ciencias Sociales de la Universidad Nacional de Quilmes. Director del Proyecto de Investigación Científica y Tecnológica (PICT) "Análisis Político del Discurso e identidades políticas: estrategias teórico-metodológicas para investigar la construcción de hegemonía y el impacto hegemónico en la Argentina reciente", auspiciado por la Agencia Nacional de Promoción de la Investigación, el Desarrollo Tecnológico y la Innovación (AGENCIA I + D), Ministerio de Ciencia, Tecnología e Innovación, República Argentina. Sus líneas de investigación se vinculan con las contribuciones de la teoría discursiva de la hegemonía para la investigación de identidades, fenómenos y procesos sociopolíticos contemporáneos. Publicaciones recientes: 1) Fair, Hernán(2021), "Teoríalacanianay Análisis Político delDiscurso. Estrategias analíticas para la investigación social”, en Studia Politicae, vol.52,Argentina:UniversidadCatólicadeCórdoba;2)Fair,Hernán(2020), "Interpelaciones, disputas en torno al modelo de acumulación y eficacia hegemónica: el proyecto de Déficit Cero de la Alianza”, en Trabajo y Sociedad, vol. 21, núm. 35, Argentina: Universidad Nacional de Santiago del Estero; 3) Fair, Hernán (2019), "Análisis Político del Discurso e investigación empírica: herramientas teóricas y estrategias metodológicas para estudiar identidades y procesos políticos desde América Latina”, en Ciencia Política, vol. 27, núm. 14, Colombia: Universidad Nacional de Colombia. 